\title{
IMÁGENES EN CERÁMICA DE LA REGIÓN DE FIAMBALÁ (CATAMARCA, ARGENTINA). CAMBIOS Y CONTINUIDADES ENTRE LOS SIGLOS IV Y XV
}

\author{
IMAGES IN POTTERY FROM THE REGION OF FIAMBALÁ \\ (CATAMARCA, ARGENTINA). CHANGES AND CONTINUITIES \\ BETWEEN THE IV AND XV CENTURIES
}

\begin{abstract}
Mara Basile ${ }^{1}$
Este trabajo se orienta a analizar la diversidad y la variabilidad espacio-temporal de los repertorios temáticos, los soportes y los recursos visuales registrados en las manifestaciones desplegadas en la cerámica de la región de Fiambalá (Catamarca). A través de esto buscamos modelar las continuidades y discontinuidades de las prácticas de construcción de estas imágenes entre los siglos IV y XV evitando la extrapolación de secuencias cerámicas extra-regionales que han conducido a desarticular la dinámica del proceso local. Para ello trabajamos con una muestra compuesta por 1.511 manifestaciones desplegadas en soporte cerámico que resultan del relevamiento de materiales fragmentarios y piezas enteras recuperadas de manera diversa en distintos contextos de la región. En esta dirección: (i) se consideran las particularidades de los soportes expresivos, para evaluar sus dimensiones y la forma de estructurar sus espacios plásticos, (ii) se definen los repertorios temáticos desplegados en ellos; y (iii) se analizan los recursos visuales utilizados para su realización a través de métodos estadísticos multivariados.
\end{abstract}

Palabras claves: análisis visual, piezas enteras y fragmentos cerámica, Fiambalá-Noroeste argentino.

This paper aims to analyze the spatio-temporal diversity and variability of the thematic repertoires and visual resources deployed in the production of ceramics from the region of Fiambalá (Catamarca), Argentina, between the IVth and XVth centuries. Through this analysis, we seek to model the continuities and discontinuities involved in the creation of this imagery, while avoiding references to extra-regional ceramic sequences-a practice that has led to a basic misunderstanding of the dynamics of local processes. To this end, we analyze a total of 1,511 visual manifestations deployed in ceramic media recorded in a study of both complete and fragmentary vessels recovered through various methods in different regional contexts. In the study, we consider (i) the particularities of the visual means to assess their dimensions and the ways in which their plastic spaces are structured; (ii) the thematic repertoires displayed; and (iii) the visual resources used in their production via multivariate statistical methods.

Key words: Visual analysis; complete and fragment ceramic vessels; Fiambalá-Northwest Argentina.

Durante el desarrollo de la disciplina arqueológica el estudio de las manifestaciones visuales ha sido enfocado de modos muy diversos connotando el enfoque teórico general de quien lo encaraba (Morphy y Perkins 2006). Por mucho tiempo éstas fueron puestas al servicio del establecimiento de tipologías y secuencias cronológicas (Balesta y Williams 2007; Conkey 1990; entre otros). Estas periodizaciones debían facilitar el ordenamiento de la variabilidad y en simultáneo la mejor comparación de los estudios interregionales. Sin embargo, específicamente respecto del análisis de las manifestaciones desplegadas en cerámica, la ausencia de unidades precisas ha conducido a que gran parte de las historias locales, y en especial la de la región de Fiambalá (Catamarca, Argentina), sean explicadas a través de la extrapolación de secuencias extrarregionales o de la construcción de nuevas "entidades culturales” (González y Sempé 1975; Sempé 1976, 1977; entre otros). Esto llevó a configurar un relato rupturista del pasado que sostenía el reemplazo de una "cultura" por otra a lo largo del tiempo, tendiendo a homogeneizar, comprimir y ocultar la diversidad propia de cada región. Si bien hace ya unos años que han comenzado a ser cuestionadas y redefinidas (Páez y Giovanetti 2008; Quiroga 2007; Scattolin 2007; entre otros), todavía hoy esas periodizaciones continúan teniendo vigencia en el área valliserrana del noroeste argentino (NOA).

En la región de Fiambalá (Figura 1), los trabajos del Proyecto Arqueológico Chaschuil-Abaucán (PACh-A $)^{1}$ han permitido emprender la revisión

1 Conicet. Museo Etnográfico J.B. Ambrosetti, Facultad de Filosofía y Letras, Universidad de Buenos Aires, Moreno 350 (1091), Ciudad Autónoma de Buenos Aires, Argentina. mara_basile@yahoo.com.ar 


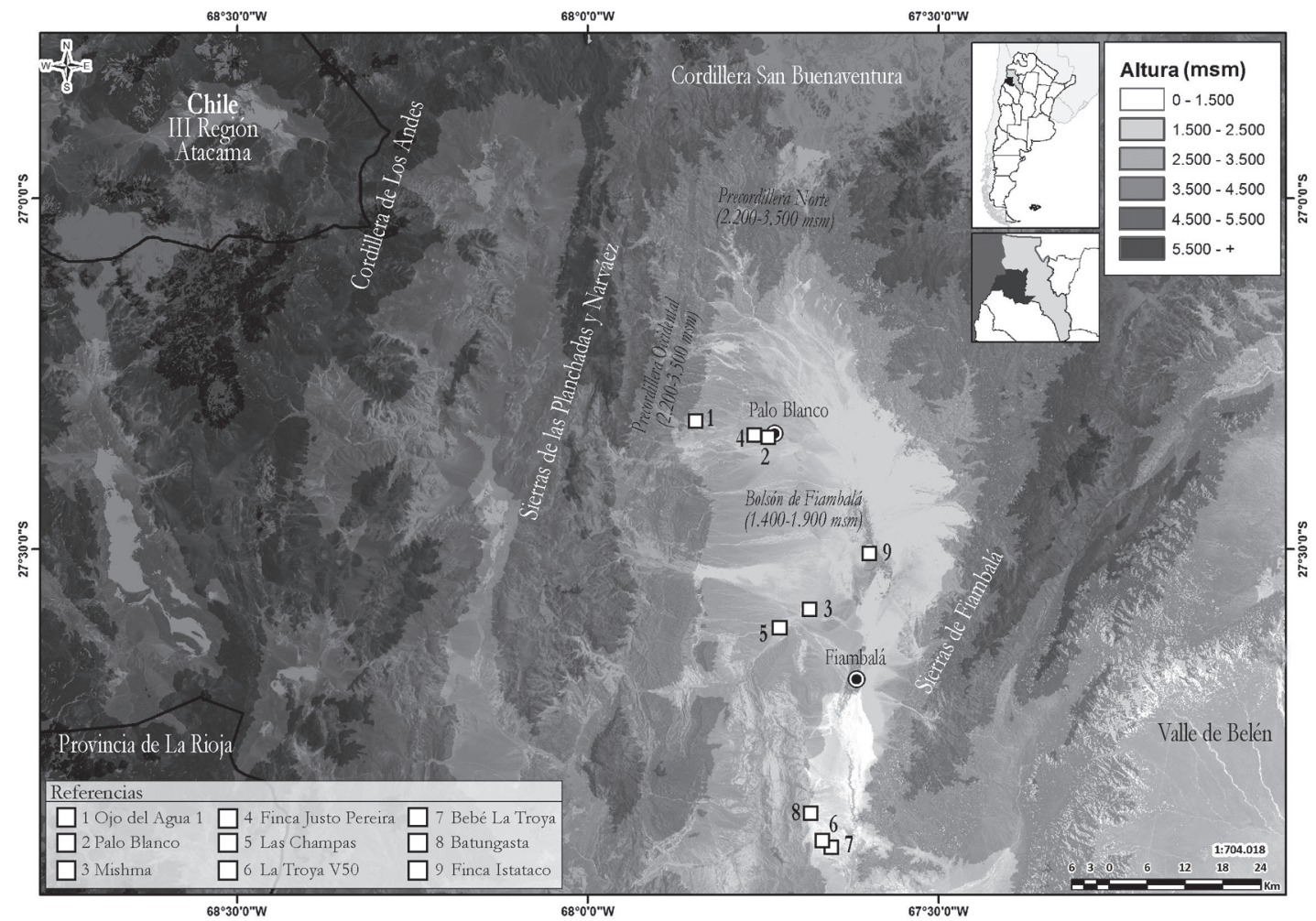

Figura 1. Ubicación espacial de los sitios de procedencia de los materiales cerámicos analizados. Spatial location of the sites of origin of the ceramic materials analyzed.

de esta situación. Fue dentro de ese sólido marco que comenzamos analizando las manifestaciones visuales desplegadas en la cerámica regional, integrando los materiales completos depositados en las colecciones museográficas con los fragmentarios recuperados de sitios con registros de excavación precisos y calibrados temporalmente.

Iniciamos ese recorrido considerando que a través de la realización de ciertas imágenes de determinada manera y en soportes particulares se definen formas de mirar, de comprender, de experimentar y de relacionarse con el paisaje que se habita y se construye (Gallardo 2005; Gell 1988; Ingold 2000; Morphy 2009). Además, como fueron las manos de la gente las que estuvieron grabando, pintando o modelando las imágenes y utilizando esos objetos en situaciones particulares, esas prácticas no son estáticas sino dinámicas. Fueron transformándose a lo largo del tiempo pero no en forma disociada sino articulada con las imágenes y formas de hacer de un pasado reciente que estaba disponible justamente en esos objetos que tienen la particularidad de perdurar en el tiempo, sujetos a interpretaciones y reinterpretaciones. En consecuencia, enfocamos el proceso manteniendo una perspectiva regional y temporalmente extensa orientada a modelar los cambios y continuidades en las imágenes y en la forma en que éstas se realizaron a lo largo del tiempo.

La necesidad de acotar espacialmente el problema a la región de Fiambalá, ubicada en el oeste tinogasteño de la provincia de Catamarca (noroeste argentino) obedece a las características particulares que presenta y que surgen de los años de producción del PACh-A (Ratto 2007; Ratto y De Nigris 2012; Ratto et al. 2004; 2008; 2013; entre otros). Estas particularidades determinan que las periodizaciones y los procesos definidos para otras regiones del NOA no se ajusten a las evidencias locales. En consecuencia, su extrapolación conduce a desarticular un proceso articulado de manera diferente donde las evidencias materiales de momentos tempranos perduran en el tiempo solapándose con las que se asocian a los momentos más tardíos vinculadas con el movimiento de pueblos resultante de la ocupación incaica de la región (Orgaz y Ratto 2012, 2013; Ratto 2013). La articulación de las distintas líneas de investigación 
de la cultura material y de los estudios paleoambientales permitió delinear el paisaje arqueológico de la región de Fiambalá para el lapso comprendido entre los siglos IV y XV que se caracteriza por la dispersión de sus asentamientos y la baja densidad poblacional. Al respecto, Ratto y Boixadós (2012) proponen que el proceso social transcurre en gran parte al ritmo y condicionamientos impuestos por los momentos de inestabilidad ambiental que generaron el despoblamiento y el repoblamiento de la región. Sostienen, tal como indican los estudios paleoambientales realizados (Montero et al. 2010; Ratto et al. 2013), que las fluctuaciones climáticas y la actividad volcánica explosiva y sísmica recurrente durante el Holoceno Medio y Tardío generaron ambientes inestables que hicieron poco viable la ocupación de las tierras bajas del bolsón de Fiambalá (1.400-1.900 msm) alrededor del año 1.000 d.C. Esto habría ocasionado el desplazamiento de los grupos agropastoriles a las tierras altas de la precordillera occidental y norte (2.200$3.500 \mathrm{msm}$ ), ya que los ecosistemas del fondo de valle fueron seriamente impactados y su recomposición ambiental demandó varias décadas. Recién en algún momento posterior al año 1.250 d.C., estas tierras comenzaron a ser reocupadas con el ingreso de nuevas poblaciones provenientes de los valles del oriente catamarqueño (Belén) y del norte de La Rioja. En síntesis, el proceso social regional está conformado por las poblaciones locales del primer milenio, que continuaron con sus modos de vida en las tierras altas precordilleranas, a las que se incorporaron las poblaciones que ingresaron al valle luego del año 1.250 d.C. posiblemente en el marco de la conquista incaica (Orgaz y Ratto 2012, 2013; Ratto 2013).

En este marco, este trabajo se orienta a analizar la diversidad y la variabilidad espacio-temporal de los repertorios temáticos, los soportes y los recursos visuales registrados en las manifestaciones visuales desplegadas en la cerámica de la región de Fiambalá modelando las continuidades y discontinuidades de las prácticas de construcción de estas imágenes entre los siglos IV y XV.

Corresponde aclarar antes de continuar que a lo largo de este texto hemos decidido evitar el uso del concepto representación, dado que los límites precisos entre la figuración y la no figuración son muy difíciles de establecer, ya que esa distinción reside en el desconocimiento del código visual subyacente (Fiore 2012; Groupe $\mu 1993$ ). En contraste recurrimos a la categoría de imagen o manifestación visual que consideramos menos ligadas a la noción de semejanza, simulacro o copia de lo real y que nos permiten pensar en su pluralidad, en su historicidad y en las dinámicas ligadas a los soportes materiales concretos en que se despliegan (ver Black 1983; Elkins 2009; entre otros).

\section{Los Materiales Analizados}

Para cumplir con el objetivo propuesto trabajamos con una muestra compuesta por 1.511 manifestaciones desplegadas en soporte cerámico que resultan del relevamiento de materiales fragmentarios y piezas enteras recuperadas de manera diversa en distintos contextos de la región. Tal como veremos más adelante, trabajar con conjuntos fragmentarios impone limitaciones que demandan la realización de razonamientos analógicos en base a las regularidades definidas a partir del análisis exhaustivo de las piezas enteras. Por lo tanto, su estudio fue el punto de partida para la posterior inclusión de los fragmentos. Las piezas enteras que analizamos $(\mathrm{N}=119)$, en cuyas superficies se documentaron 1.111 manifestaciones, proceden de contextos funerarios conocidos e intervenidos: (i) en la década de 1940, como los cementerios de Istataco y Huanchin; (ii) por pobladores locales, como las tumbas en cista de la Finca Justo Pereira y Las Champas; e (iii) intervenciones realizadas en el marco del PACh-A. Todos estos materiales se encuentran depositados en museos provinciales y comunales regionales y extrarregionales. Por su parte, los materiales fragmentarios $(\mathrm{N}=245)$ en los que se relevaron las 400 manifestaciones restantes, fueron recuperados en diversas intervenciones realizadas por el PACh-A en sitios arqueológicos emplazados en las distintas ecozonas de la región: (i) Ojo del Agua 1 (OA1) se localiza en la precordillera occidental (ii) la localidad arqueológica de Palo Blanco (PB) en el valle Alto, (iii) las Áreas Mishma (Msh) y Las Champas (LCh) en el valle medio; y (iv) Batungasta (BT) y la localidad La Troya-V50 (LT) en el valle bajo (Figura 1).

\section{Las Herramientas Metodológicas}

Consideramos que trabajar con esta gran cantidad de manifestaciones visuales $(\mathrm{N}=1.511)$ requiere detallar en forma explícita, no ambigua y replicable, los criterios metodológicos utilizados 
y las variables analíticas definidas, realizando un tratamiento estadístico multivariado que permita un análisis exploratorio e integral fundamental para el ordenamiento inicial de la variabilidad registrada. Esta propuesta demanda organizar el análisis en diferentes etapas y fue presentada en detalle en trabajos anteriores (Basile 2012; Basile y Ratto 2011) por lo que aquí se recorre sintéticamente. Incluimos un diagrama de flujo que condensa los distintos niveles analíticos y la forma en que éstos se articulan para facilitar el seguimiento de la lógica del procedimiento metodológico propuesto (Figura 2).

\section{EI nivel de los soportes. Definiendo los espacios plásticos}

Dado que la muestra está compuesta por materiales que no brindan la misma calidad de información respecto de las preguntas que intentamos responder, fue fundamental la sistematización de las regularidades existentes a nivel de las piezas enteras para posteriormente integrar los fragmentos al análisis. Este nivel se orientó a definir los espacios plásticos disponibles para la intervención visual considerando una serie de variables. A saber:

\section{(a) Forma de la pieza}

Los trabajos que inicialmente abordaron la descripción de materiales cerámicos apuntando a su clasificación tendieron a establecer una relación entre la forma y la función de las piezas que condujo al uso de categorías morfológicas que remitían a una funcionalidad para la que no siempre se tenía evidencia suficiente (Balesta 2000). Esto condujo a que distintos investigadores clasifiquen una misma pieza de maneras diferentes. Además, las dimensiones de muchos de los fragmentos de la muestra impiden distinguir entre categorías morfológicas más ajustadas. Por lo tanto y dado que el objetivo de la definición de la forma aquí es el de determinar las dimensiones del espacio plástico que ofrece cada pieza, decidimos utilizar una categoría más amplia para describirlas. Así las clasificamos en seis categorías formales: piezas abiertas de contornos simples o compuestos y piezas cerradas de contornos inflexionados, subglobulares o compuestos. Para ello consideramos, por un lado, la relación entre el diámetro máximo y el de la boca y, por el otro, la existencia o no de puntos de inflexión o intersección en sus perfiles (Balfet et al. 1992).

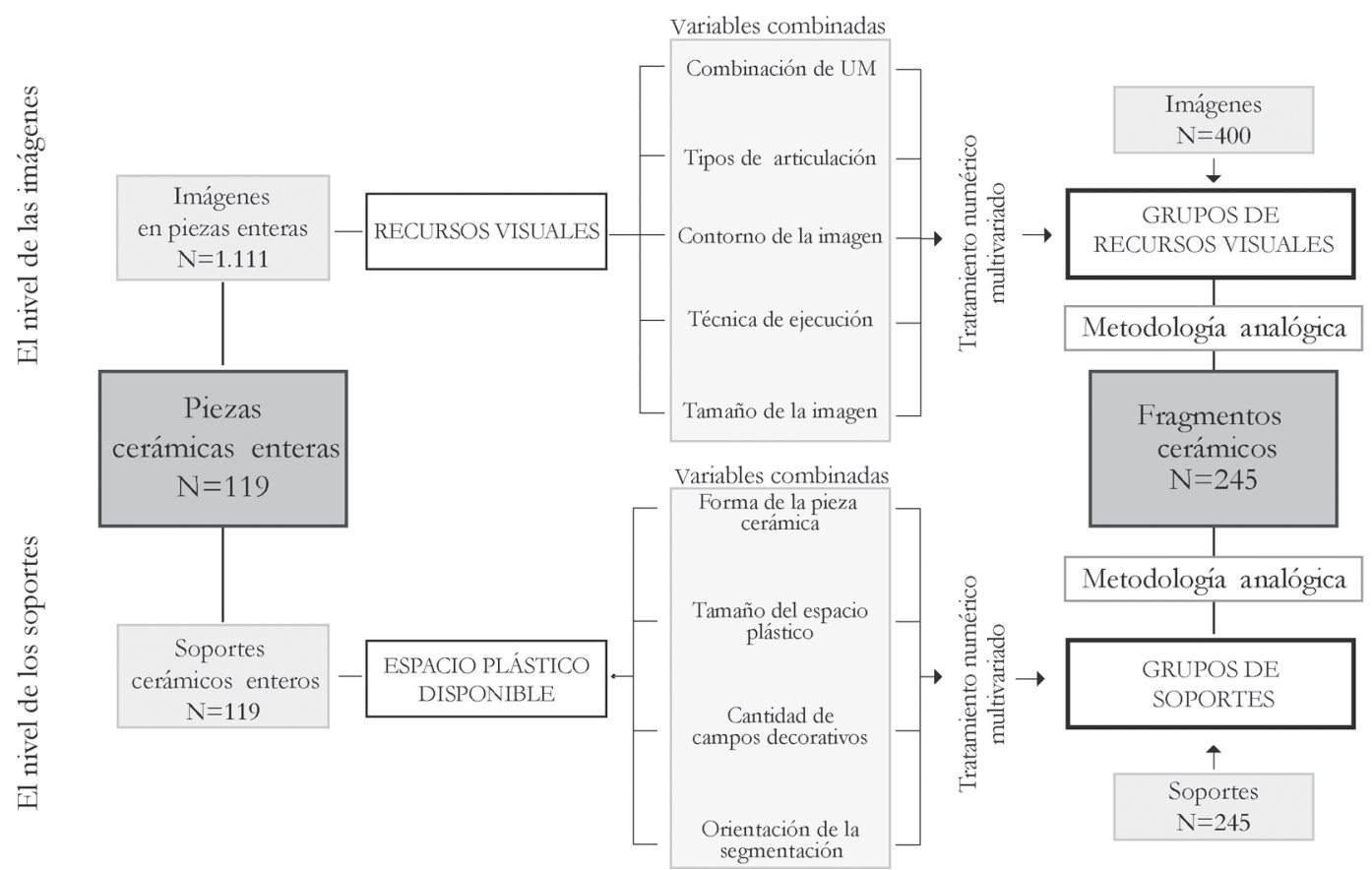

Figura 2. Diagrama de flujo ejemplificando la integración de los niveles de análisis del procedimiento metodológico propuesto para la definición de los Grupos de Soportes y de Recursos Visuales y la inclusión de los fragmentos.

Flowchart illustrating the integration of the analytical levels of the methodological procedure proposed for the definition of Media Groups, Visual Resources Groups, and the integration of the fragments. 


\section{(b) Tamaño del espacio plástico}

Para calcular la superficie del espacio plástico se aplicó la fórmula para el cálculo del área lateral externa del cilindro y se utilizó un promedio de los diámetros presentes en cada pieza según sus contornos (Basile y Ratto 2011). Además, las piezas tienen un espacio interno disponible para su intervención visual que también fue considerado ${ }^{3}$. Las superficies calculadas fueron organizadas en una escala ordinal por rangos de tamaño: (i) pequeño - $0-1.250 \mathrm{~cm}^{2}$-; (ii) mediano $-1.250-2.500 \mathrm{~cm}^{2}-$; (iii) grande $-2.500-3.750 \mathrm{~cm}^{2}-$; (iv) muy grande -mayor a $3.750 \mathrm{~cm}^{2}-$

\section{(c) Cantidad de campos decorativos intervenidos visualmente}

Consideramos que el espacio plástico disponible en cada pieza puede presentarse o no segmentado en campos decorativos que son las zonas que se delimitan a través del trazado explícito, del marcado de algún punto angular en el perfil o de la simple interrupción o cambio de la decoración sobre la superficie. De esta manera se contabilizó la cantidad de campos decorativos en los que se despliegan las imágenes, definiéndose 12 combinaciones posibles entre las superficies interna y externa de las piezas (Basile y Ratto 2011).

\section{(d) Orientación de la segmentación del espacio plástico}

También se consideró la orientación en que se marca esta segmentación que puede tener un sentido horizontal, vertical o resultar de una combinación entre ambos y clasificarse como mixta. En los casos en los que el diseño se extiende en forma completa por alguna de las superficies de la pieza, este espacio se considera como no segmentado.

\section{El nivel de las imágenes}

El segundo nivel de análisis se orientó a la caracterización de los repertorios temáticos. Para la organización de las imágenes ${ }^{3}$ se usó como base la clasificación elaborada por Aschero (2006, 2013) para el estudio del arte rupestre de la vecina región de Antofagasta de la Sierra. Sus categorías de subclases, clases y conjuntos de clase presentan niveles de inclusión progresivos. Esto nos permitió articular diferentes grados de resolución en el análisis e integrar en otros trabajos estas imágenes con las rupestres (Basile 2011, 2012; Basile y Ratto 2011).

\section{El nivel de los recursos visuales}

El tercer nivel de análisis apuntó a delinear los recursos visuales (Basile 2011; Basile y Ratto 2011) utilizados en la realización de las imágenes. Consideramos que éstos involucran una selección de elementos visuales que manifiestan la existencia de preferencias estéticas y conocimientos compartidos en el marco del entramado social particular en que son utilizados. Su definición demandó la construcción de variables con estados específicos:

\section{(a) Combinación de unidades morfológicas (UM):}

Consideramos que todas las imágenes analizadas están compuestas por un número determinado de elementos mínimos que denominamos UM (sensu Aschero 1975). En trabajos previos (Basile 2011, 2012; Basile y Ratto 2011) definimos ocho tipos de UM básicas a partir de los trabajos de Kandinsky (2007 [1926]), Scott 1962 [1951] y Aschero (1975). Éstas pueden presentarse aisladamente, pero las imágenes suelen resultar de la combinación de una única unidad en sí misma o de más de una de ellas. En general, las manifestaciones tienden a resolverse por medio de combinaciones de una o dos UM, siendo los casos que involucran mayores cantidades, los menos recurrentes en esta muestra (Figura 3a).

\section{(b) Tipos de articulaciones:}

A fin de analizar la forma en que estas UM se articulan para configurar las imágenes se definieron diferentes tipos de articulaciones sobre la base de los trabajos de Gardin (1978) y Aschero (2013). Esta variable presenta ocho estados compuestos por los cuatro tipos de articulaciones básicas, incluida su ausencia (Figura 3b), y por las combinaciones posibles entre ellas.

\section{(c) Contorno:}

Se consideró la forma en que se resolvieron las imágenes tomando en cuenta su contenido, ya que una misma figura puede recortarse del fondo: (i) a partir del delineado de su contorno, presentando su interior "vacío", (ii) a partir del llenado de su 


\begin{tabular}{|c|c|c|c|c|}
\hline \multicolumn{2}{|c|}{ (a) Tipo de unidad morfológica } & \multicolumn{3}{|c|}{ (b) Tipo de articulación } \\
\hline U.M 1: Puntos & - & $\mathrm{N}^{\circ} 1$ : No articulada & . & \\
\hline $\begin{array}{l}\text { U.M 2: Trazos } \\
\text { rectilíneos }\end{array}$ & $\rightarrow$ & $\mathrm{N}^{\circ} 2$ : Aditiva y/o intersecta & & \\
\hline $\begin{array}{l}\text { U.M 3: Trazos } \\
\text { angulares }\end{array}$ & & No 3: Radial y/o simétrica & & \\
\hline $\begin{array}{l}\text { U.M 4: Trazos } \\
\text { libremente ondulados }\end{array}$ & $\downarrow$ & $\mathrm{N}^{\circ} 4$ : Inscripta y/o solapada & & \\
\hline $\begin{array}{l}\text { U.M 5: Trazos } \\
\text { curvilíneos simples }\end{array}$ & & (c) Cont & & \\
\hline $\begin{array}{l}\text { U.M 6: Trazos en } \\
\text { gancho }\end{array}$ & & 1. Lineal & & \\
\hline $\begin{array}{l}\text { U.M 7: Trazos } \\
\text { espiralados }\end{array}$ & & 2. Pleno & & \\
\hline $\begin{array}{l}\text { U.M 8: Elementos } \\
\text { plásticos }\end{array}$ & & 3. Relleno & & 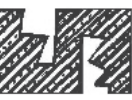 \\
\hline
\end{tabular}

Figura 3. Presentación de algunas de las variables consideradas en la definición de los recursos visuales.

Presentation of some of the variables considered in the definition of visual resources.

interior de forma plena, o (iii) presentando otros diseños como contenido interno a modo de relleno. Los tres estados de esta variable fueron registrados en la muestra analizada (Figura 3c).

\section{(d) Técnicas de ejecución:}

Las técnicas utilizadas en la modificación de los soportes (modelado, pulido en líneas, estampado, inciso, exciso, grabado y pintura) se clasificaron considerando que todas implican el uso de instrumentos o elementos particulares (porciones de pasta, puntas, pinceles o pigmentos) en momentos de ejecución específicos. Se registraron 15 combinaciones partiendo de las 7 técnicas básicas documentadas en la muestra bajo análisis.

\section{(e) Tamaño:}

El cálculo de la superficie de cada una de las imágenes se realizó considerando su alto y ancho máximos clasificándose en rangos de tamaño que definen una escala ordinal: (i) $0-250 \mathrm{~cm}^{2}$; (ii) 250 $500 \mathrm{~cm}^{2}$; (iii) $500-750 \mathrm{~cm}^{2}$; (iv) mayor a $750 \mathrm{~cm}^{2}$.

\section{La definición de los Grupos de Soportes y de Recursos Visuales}

Las variables cualitativas fueron transformadas a variables ordinales. Para el ordenamiento jerárquico de cada una de ellas se siguió una secuencia lógica basada en la aplicación de criterios que dan cuenta del incremento progresivo en la inversión de trabajo en los términos en que la define Fiore (2007), ya que coincidimos en que la producción creativa de cualquier manifestación visual involucra la conversión de materias primas específicas en imágenes por medio de técnicas e instrumentos particulares que demandan la inversión de energía, tiempo, habilidades, destreza manual, conocimiento y percepción (Fiore 2009). A continuación se ejecutó un tratamiento estadístico multivariado 
de las variables analizadas aplicando Análisis de Correspondencia Múltiple (ACM). Con los valores de los ejes factoriales obtenidos se realizó un Análisis de Conglomerados Jerárquicos (ACJ $)^{4}$ y el análisis del dendrograma resultante permitió determinar la cantidad de Grupos de Soportes (GSp) y de Recursos Visuales (GRV) que definen la muestra de piezas enteras ${ }^{5}$. La combinación de estos métodos analíticos nos permite no sólo estudiar las relaciones de interdependencia entre variables cualitativas sino también conocer cómo está estructurada esa relación (Basile y Ratto 2011).

Por su parte, los fragmentos tienen limitaciones que inciden sobre la resolución de la información que aportan en la aplicación de la metodología propuesta. Esto implica que no todos ellos permiten la determinación de las variables necesarias tanto para el análisis del nivel de los soportes como del de los recursos visuales. Sin embargo, la información visual y morfodimensional obtenida a partir de las piezas enteras y las regularidades de los estilos regionales definidas por otros investigadores (Balesta 2000; Basile 2012 [2005]; Gordillo 2009; Wynveldt 2007; entre otros) permitieron la adscripción de los fragmentos $(\mathrm{N}=245)$ y de las imágenes relevadas en ellos $(\mathrm{N}=400)$ a los distintos Grupos de Soportes y de Recursos Visuales delineados (Figura 2). Cada uno de estos Grupos integra casos que guardan similitud en el comportamiento de las variables que definen ambos niveles de análisis. Así, un Grupo de Soporte específico integra aquellas piezas enteras o parcialmente reconstruidas que tienden a compartir la (i) forma de la pieza, (ii) el tamaño del espacio plástico, (iii) la cantidad de campos decorativos y (iv) la orientación de la segmentación; y así dan cuenta de una misma forma de definir y estructurar los espacios plásticos disponibles. Por su parte, un Grupo de Recursos Visuales determinado integra aquellas imágenes relevadas en las superficies de las piezas, enteras o parcialmente reconstruidas, que tienden a compartir ciertas (i) combinaciones de UM, (ii) tipos de articulación, (iii) contorno, (iv) combinación de técnicas y (v) tamaño; y así dan cuenta de una misma forma de realización de las manifestaciones.

En síntesis, la integración al análisis de la muestra fragmentaria fue posible mediante la conducción de una metodología creativa que no brinda certezas, pero que consideramos relevante para un análisis inclusivo que refleja la realidad del tipo de materiales con los que trabajamos los arqueólogos.
De esta manera, no sólo se integran los fragmentos a un análisis visual, sino que también se revaloriza la importancia del estudio de colecciones de piezas enteras cuya referencia es fundamental para poder llevarlo a cabo (Basile 2011).

\section{El manejo del tiempo}

En este punto cabe aclarar que tanto las piezas enteras como los fragmentos se corresponden con diferentes estilos decorativos tradicionalmente utilizados como diagnóstico temporal relativo para organizar el universo cerámico ante la falta de fechados radiocarbónicos precisos. Sin embargo, aquí decidimos tomar como punto de partida para el análisis temporal exploratorio que presentamos, las dataciones obtenidas de los materiales orgánicos asociados a los fragmentos o piezas cerámicas recuperadas durante la excavación de los sitios arqueológicos ${ }^{6}$ que se presentan en la Tabla 1 (años calendáricos calibrados con el programa Calib 6.0.1, Stuiver y Reimer 1993) que se encuentran íntegramente publicados por Ratto (2013). Dado que excede los límites de este trabajo, en esta tabla también se consignan las referencias bibliográficas necesarias para ampliar la información contextual de cada sitio. Esta decisión metodológica nos permitió evaluar en forma preliminar la existencia de (i) manifestaciones, (ii) formas de uso de los espacios plásticos y (iii) recursos visuales, que trascendían los límites impuestos por las periodizaciones dentro de la región de Fiambalá.

\section{Análisis y Resultados: Delineando Continuidades y Cambios a lo Largo del Tiempo}

En sintonía con los niveles analíticos propuestos organizamos la presentación de los resultados en dos ámbitos diferentes, uno dirigido a la definición de los espacios plásticos intervenidos y el otro a la delineación de los recursos visuales utilizados en la realización de las imágenes desplegadas en ellos.

\section{Los espacios plásticos visualmente intervenidos}

La integración de las cuatro variables presentadas (forma de la pieza, tamaño del espacio plástico, cantidad de campos decorativos intervenidos y orientación de la segmentación) siguiendo 
Tabla 1. Rangos temporales definidos en función de los fechados de los sitios de procedencia de la muestra. Extraídos de Ratto (2013).

Temporal ranges defined according to the dating of sites of origin of the samples.

(Taken from Ratto 2013).

\begin{tabular}{|c|c|c|c|c|c|c|}
\hline \multicolumn{2}{|c|}{ Rangos temporales } & Nombre/sigla & $\begin{array}{l}\text { Sigla lab. } \\
\text { y número } \\
\text { análisis }\end{array}$ & $\begin{array}{c}\text { Fechado } \\
\text { radiométrico }\end{array}$ & $\begin{array}{l}\text { Años cal. d.C. } \\
\text { (1 sigma) }\end{array}$ & $\begin{array}{c}\text { Referencia } \\
\text { bibliográfica }\end{array}$ \\
\hline \multirow{6}{*}{$\begin{array}{c}\text { Antes del año } \\
1.000 \text { d.C. }\end{array}$} & \multirow{2}{*}{1} & \multirow{2}{*}{ Palo Blanco-PB-NH3 } & AA65138 & $1.566 \pm 39$ & $458-535$ & \multirow{2}{*}{$\begin{array}{l}\text { Bonomo et al. 2010; } \\
\text { Feely y Ratto } 2009\end{array}$} \\
\hline & & & AA65139 & $1.467 \pm 39$ & $596-639$ & \\
\hline & 2 & La Troya-V50 & AC1718 & $1.250 \pm 85$ & $687-784$ & Feely y Ratto 2009 \\
\hline & \multirow{2}{*}{3} & \multirow{2}{*}{ Palo Blanco-PB-NH6 } & AA81735 & $1.236 \pm 37$ & $693-748$ & \multirow{2}{*}{ Ratto y Basile 2010} \\
\hline & & & AA 81736 & $1.194 \pm 37$ & $800-882$ & \\
\hline & 4 & Ojo de Agua 1 & AA89937 & $990 \pm 45$ & $994-1.047$ & $\begin{array}{c}\text { Feely y Ratto } 2009 ; \\
\text { Ratto et al. } 2008\end{array}$ \\
\hline \multirow{6}{*}{$\begin{array}{c}\text { Después del } \\
\text { año } 1.250 \text { d.C. }\end{array}$} & 5 & Finca Istataco & AA72750 & $717 \pm 34$ & $1.269-1.299$ & $\begin{array}{c}\text { Dreidemie 1951, } \\
\text { 1953, Basile y Ratto } \\
2011\end{array}$ \\
\hline & \multirow{3}{*}{6} & Las Champas & AA89939 & $600 \pm 52$ & $1.304-1.365$ & \multirow{3}{*}{$\begin{array}{c}\text { Basile y Ratto } 2011 \\
\text { Ratto, Feely y Basile } \\
2007\end{array}$} \\
\hline & & Bebé La Troya & AA62809 & $603+-37$ & $1.305-1.334$ & \\
\hline & & Finca Justo Pereira & AA65133 & $589 \pm 44$ & $1.305-1.355$ & \\
\hline & 7 & Mishma 7 & AA69979 & $514 \pm 35$ & $1.405-1.435$ & \multirow[b]{2}{*}{ Orgaz et al. 2007} \\
\hline & 8 & Batungasta & $\mathrm{AC} 172$ & $380 \pm 60$ & $1.445-1.522$ & \\
\hline
\end{tabular}

los criterios explicitados, permite definir la forma, las dimensiones y la manera en que se delimita el espacio plástico disponible para la intervención visual en los materiales analizados. El análisis generó tres ejes factoriales de los cuales los dos primeros explican el $90,67 \%$ de la varianza total de la muestra. Luego de la realización del ACJ, se observa que los ejes se organizan en seis Grupos de Soportes (GSp) (Figura 4) cuyas particularidades se sintetizan en la Figura 5.

En este nivel de análisis se observa que no todos los Grupos de Soportes se encuentran representados en los distintos rangos temporales definidos (Tabla 1). Tal como vemos en la Figura 6a, sólo los GSp 1, 2 y 6 tienden a registrarse a lo largo de toda la secuencia. Todos ellos integran piezas abiertas de contornos simples o compuestos de dimensiones diversas. Respecto de los tres restantes, ni el Gsp 3 ni el 5 se registran en contextos anteriores al año 1.250 d.C. Recordemos que estos GSp integran todas las piezas cerradas compuestas e inflexionadas de la muestra, respectivamente. Por último, el GSp 4, que incluye las piezas cerradas subglobulares, sólo se documenta en contextos datados entre los años 600 y 1.000 d.C. (Figura 6a).

Esto indica que hay ciertos modos de definir y segmentar los espacios plásticos en las piezas analizadas que tienden a ser exclusivos de momentos de tiempo más acotados. Esto atañe específicamente a las piezas cerradas de la muestra (GSp 3, 4 y 5). En contraste, en el caso de las piezas abiertas (GSp 1,2 y 6) se observa que los tamaños y la forma en que se utilizan sus espacios plásticos, en términos de segmentación y orientación, tienden a "perdurar" en el tiempo durante toda la secuencia considerada.

\section{Las imágenes y los recursos visuales utilizados en su resolución}

En las superficies de las piezas enteras y fragmentarias analizadas se documentaron 1.511 imágenes que se clasificaron en 19 clases y 59 subclases. Además, se construyó la unidad conjuntos de clase para lograr una mejor expresión gráfica de la interrelación entre variables. Las manifestaciones se organizaron en: (i) Diseños no figurativos primarios (NFP), (ii) Diseños no figurativos compuestos $(\mathrm{NFC})^{7}$, (iii) Rastros (R-P), (iv) Figuras zoomorfas (FZ) y (v) Figuras Humanas (FH). Este nivel es muy inclusivo, pero permite tener un panorama general para explorar conjuntos de imágenes particulares. De este modo se destacan las siguientes tendencias: - Los diseños no figurativos primarios se registran en los distintos GSp definidos y a lo largo de toda la secuencia considerada. Si afinamos el análisis dentro de esta categoría, las subclases 


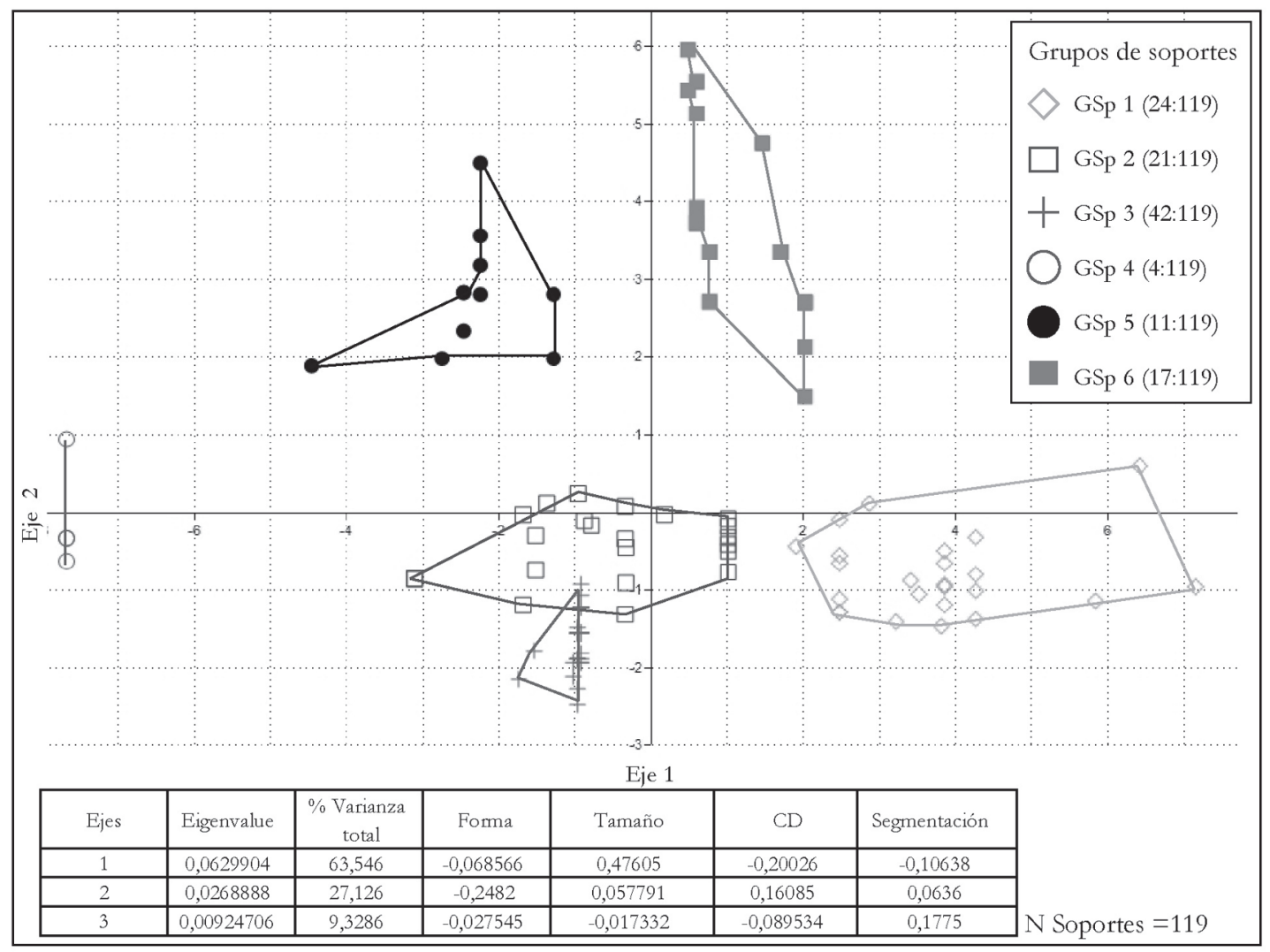

Figura 4. Relación de los Ejes factoriales 1 y 2 del Análisis de Correspondencia Múltiple. Ploteo en función de los seis Grupos de Soportes definidos luego de la aplicación del Análisis de Conglomerados Jerárquicos.

Relation of factorial axes 1 and 2 of the Multiple Correspondence Analysis. Plotting according to the six Groups of Media defined after the application of Hierarchical Cluster Analysis.

más recurrentes (trazos agrupados, reticulados y círculos simples) mantienen la tendencia general.

- Los diseños no figurativos compuestos también se registran en toda la secuencia temporal, pero sus frecuencias tienden a incrementarse radicalmente a partir del año 1.250 d.C. Si los analizamos en detalle observamos que hay ciertas imágenes, como las figuras rectangulares, escalonadas, triángulos y rombos, cuya frecuencia aumenta hacia momentos más tardíos mientras que hay otras, como los círculos compuestos, los espirales y los ganchos curvilíneos, que se registran únicamente en contextos posteriores al año 1.250 d.C.

- Las figuras de rastros presentan muy baja frecuencia en toda la muestra.

- Las figuras zoomorfas se registran desde el año 600 d.C. Entre ellas, las figuras felínicas se asocian fuertemente con piezas adscritas al GSp 4 documentándose únicamente entre los años 600 y 1.000 d.C. Sin embargo, hay elementos que "felinizan" algunas imágenes de momentos posteriores al año 1.250 d.C. (manchas, fauces, colas, huellas). Estos animales felinizados (camélidos, vizcachas, serpientes) presentan muy baja frecuencia pero su registro en estos momentos más tardíos es sugestivo.

- Las figuras humanas se documentan en baja frecuencia, sólo en materiales de contextos tardíos y en todos los GSp definidos a excepción del GSp 4.

En síntesis y en sintonía con lo observado en los grupos de soportes, hay ciertas imágenes que tienden a "perdurar" en el tiempo registrándose en los distintos rangos definidos (trazos agrupados o reticulados y círculos simples) o tienden a incrementar su frecuencia hacia los momentos más 


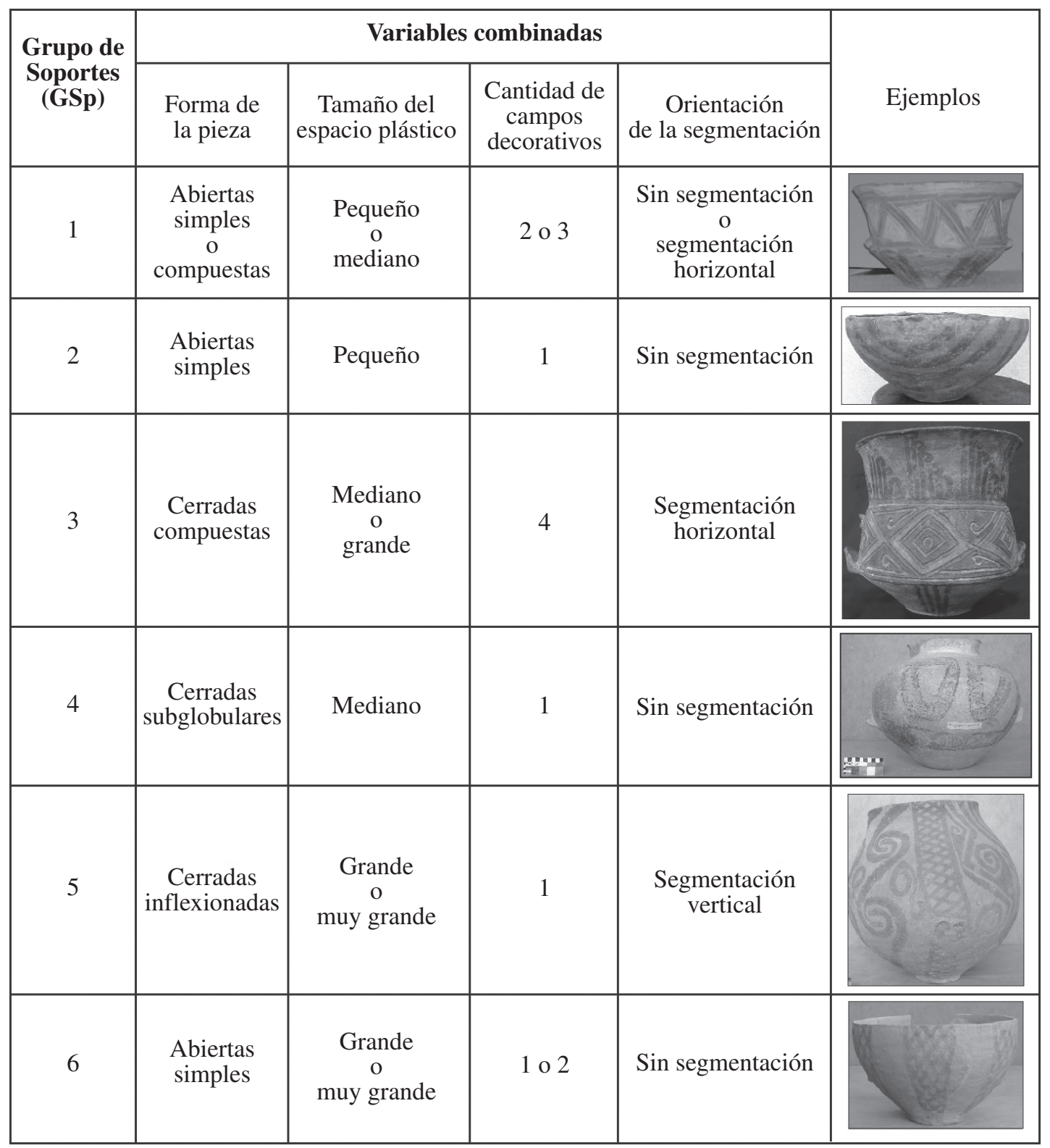

Figura 5. Síntesis de las características distintivas de los Grupos de Soportes definidos.

Synthesis of the distinctive features of the defined Media Groups.

tardíos posteriores al año 1.250 d.C. (escalonados, rectangulares, triángulos y rombos). Asimismo, hay otras imágenes que son exclusivas de materiales recuperados en contextos adscritos a rangos de tiempo más acotados (círculos compuestos, ganchos y espirales, figuras felínicas, y serpientes, entre otras).

Que las categorías de clasificación de las imágenes tiendan a permanecer en el tiempo no necesariamente implica que éstas se realicen por medio de los mismos recursos visuales. De acuerdo con la metodología propuesta, la integración de las variables definidas (combinación de UM, tipos de articulación, contorno, técnicas de resolución y tamaño) permitió definir los 10 Grupos de Recursos Visuales (GRV) utilizados para la realización de cada una de las imágenes analizadas $(\mathrm{N}=1.511)$ (Figura 7). Las particularidades de cada uno de 


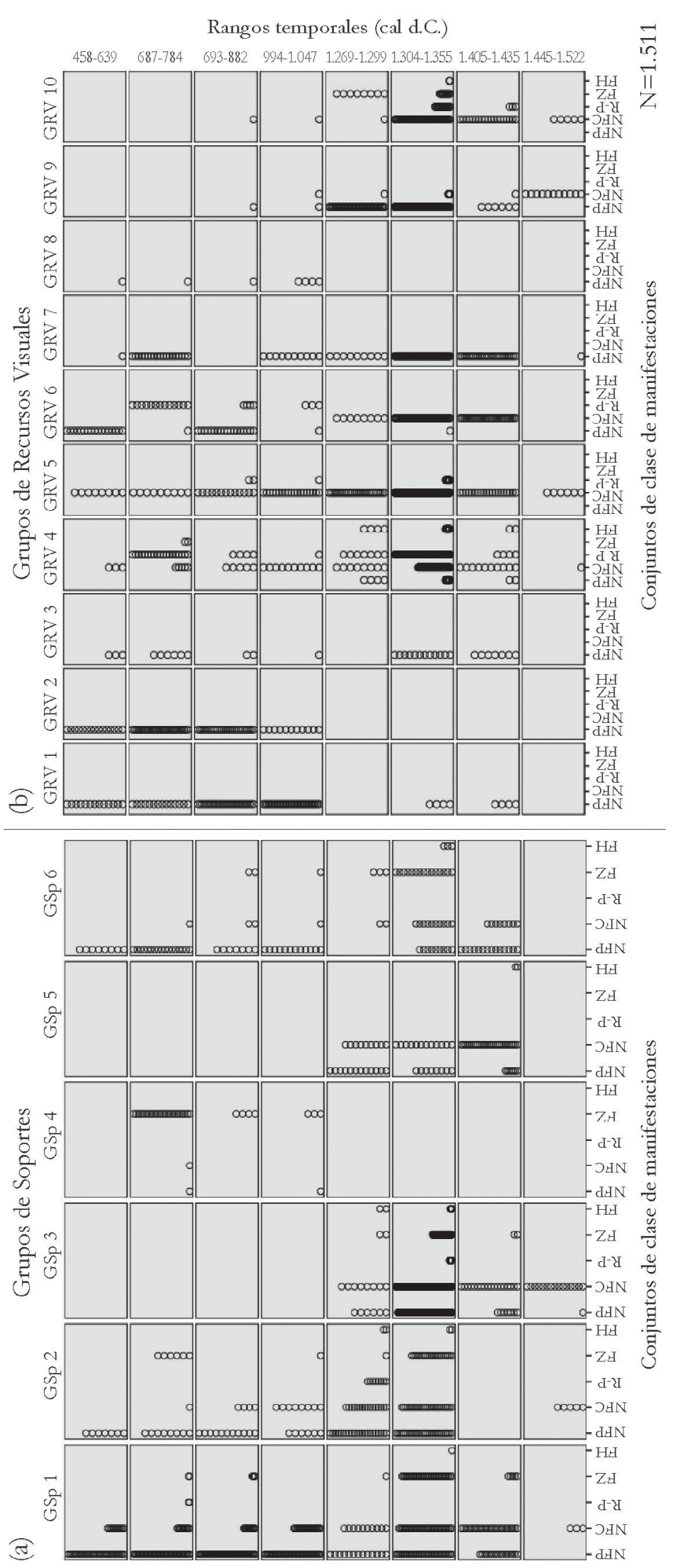

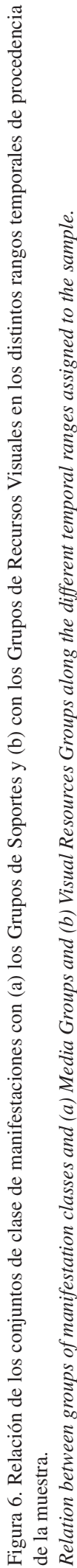




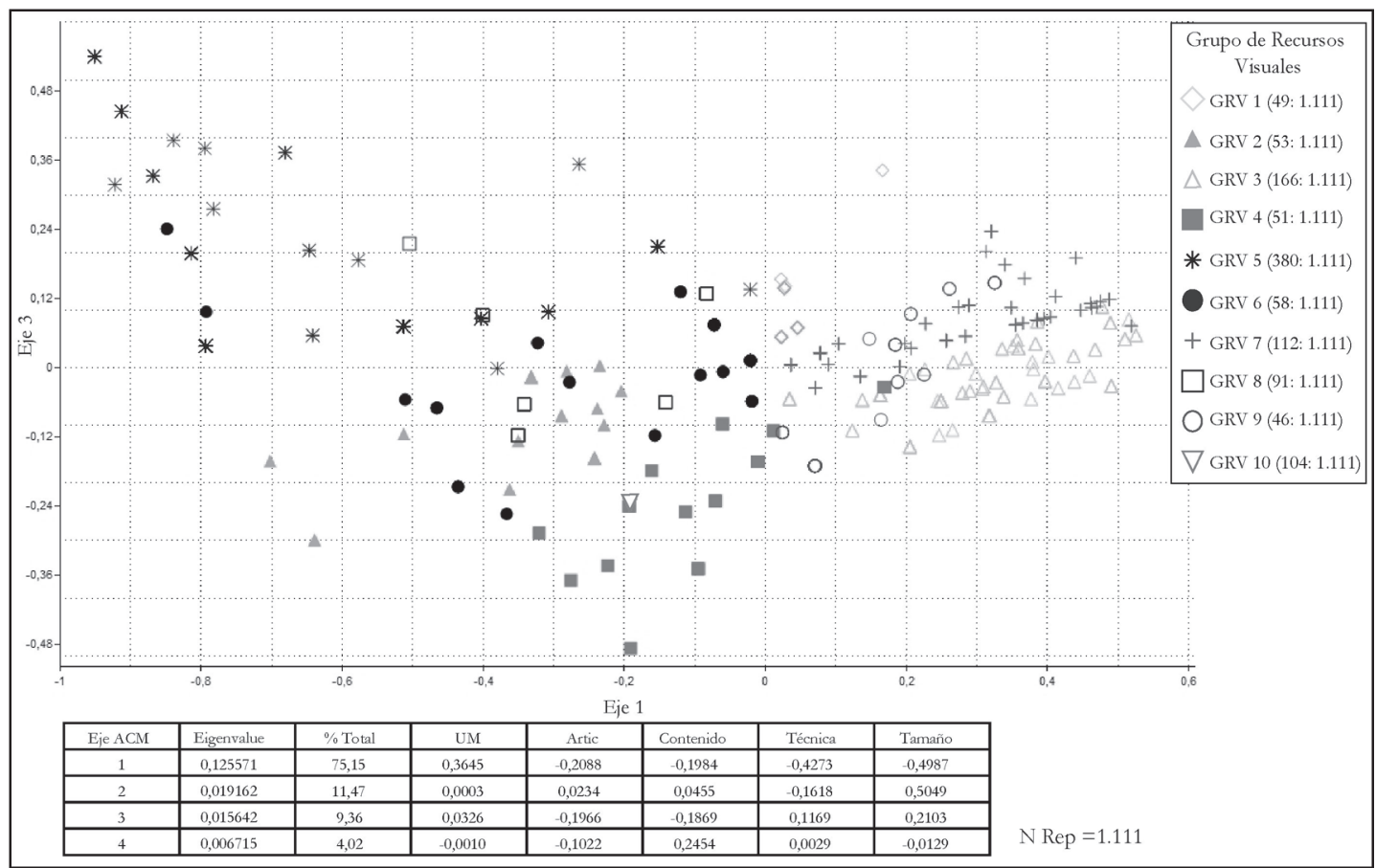

Figura 7. Relación de los Ejes factoriales 1 y 3 del Análisis de Correspondencia Múltiple. Ploteo en función de los 10 Grupos de Recursos Visuales definidos luego de la aplicación del Análisis de Conglomerados Jerárquicos.

Relation of factorial axes 1 and 3 resulting from the Multiple Correspondence Analysis. Plotting according to the 10 Visual Resources Groups defined after the application of Hierarchical Cluster Analysis.

ellos se sintetizan por cuestiones de espacio en la Figura 8.

En términos generales vemos que no se registra ningún GRV exclusivo de materiales recuperados en contextos datados con posterioridad al año 1.250 d.C. (Figura 6b). En el caso de las imágenes que incrementan su frecuencia hacia esos momentos (escalonados, rectangulares, triángulos, rombos), los recursos visuales utilizados suelen ser los que se empleaban antes del año 1.000 d.C. pero también comienzan a realizarse con recursos visuales nuevos. Esto indica que hay un incremento en la diversidad de soluciones plásticas para determinadas imágenes a lo largo del tiempo, imágenes que inicialmente se resolvían con un único GRV, a partir del año 1.250 d.C. comienzan a presentarse resueltas con una mayor diversidad de recursos visuales.

Por su parte, las manifestaciones que se registran exclusivamente en materiales procedentes de contextos adscritos a rangos temporales más acotados resultan particularmente interesantes:

- Las imágenes que sólo se registran en materiales de contextos posteriores al año 1.250 d.C. (círculos compuestos, ganchos y espirales, serpientes, animales fantásticos, lechuzas y figuras humanas) se resuelven con una diversidad de Grupos de Recursos Visuales.

- Las figuras felínicas que sólo se registran en materiales de contextos datados entre los 600 y los 1.000 años d.C., tienden a realizarse continuamente con los mismos recursos visuales.

- El caso de los animales felinizados vale la pena ser destacado. Si bien algunos son exclusivos de momentos posteriores al año 1.250 d.C. (las vizcachas y zoomorfos felinizados), otros se registran tanto en momentos tempranos (600-1.000 d.C.) como tardíos (1.250-1.355 d.C.). Resulta interesante que son justamente algunas de estas imágenes las únicas figurativas que tienden a "perdurar" a lo largo de la secuencia definida. Sin embargo, se resuelven en los distintos rangos temporales por medio de recursos visuales diferentes. Insistimos en que resulta sugestivo, ya que las figuras felínicas son exclusivas de momentos tempranos, que las huellas felínicas y las figuras de animales felinizados se registren también en los momentos más tardíos. En general, las figuras felinizadas 


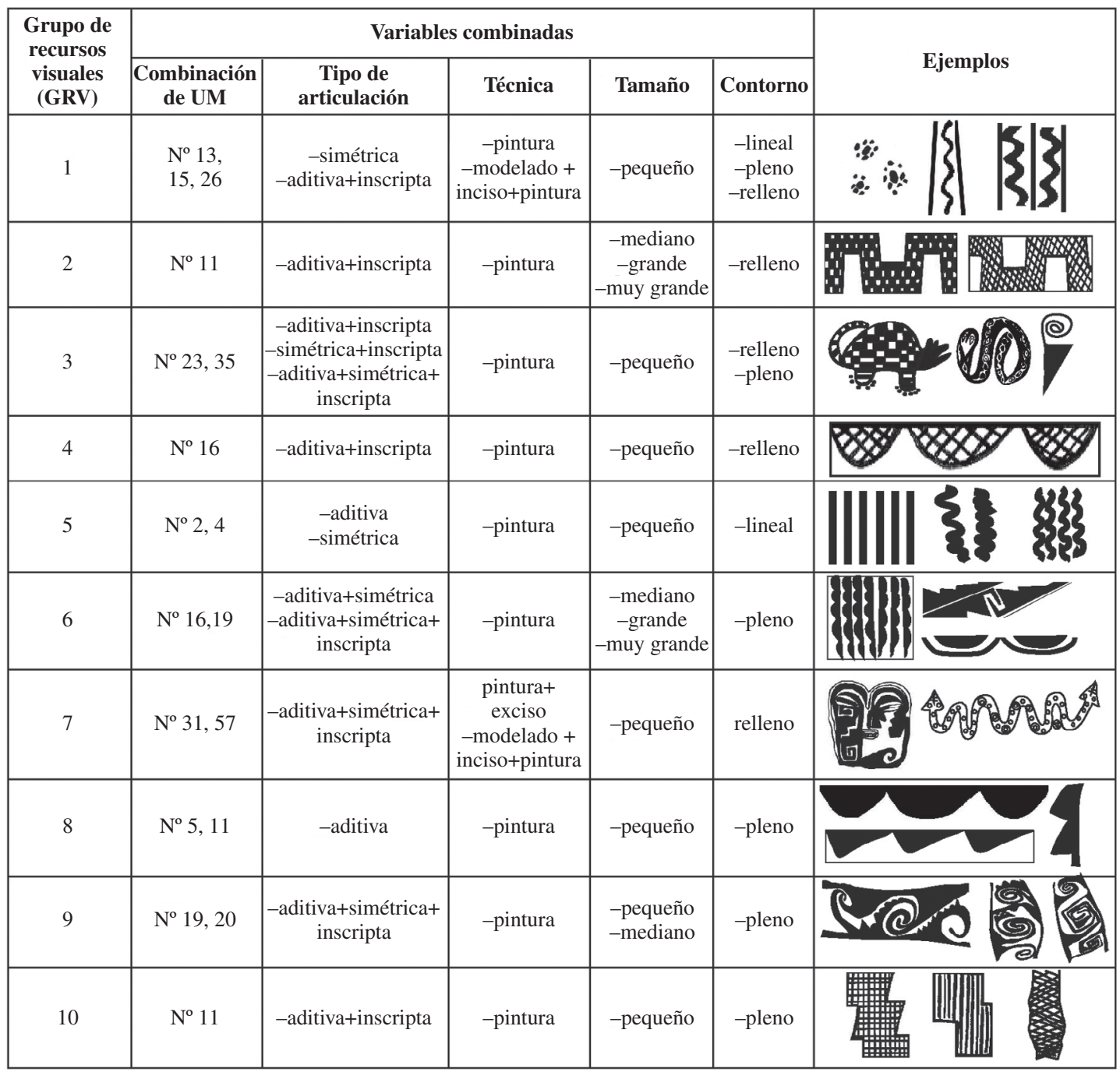

Figura 8. Síntesis de las características distintivas de los Grupos de Recursos Visuales definidos.

Synthesis of the distinctive features of the Visual Resources Groups defined.

posteriores al año 1.250 d.C. se realizan con GRV y se despliegan en piezas distintas de las que se utilizaban durante el primer milenio. Esto puede estar implicando que hay ciertas imágenes que siguen vigentes y son incorporadas o reinterpretadas y resignificadas dentro del nuevo contexto, trazando conexiones con las narrativas de los momentos previos (Basile 2011; Ratto y Basile 2013).

En resumen, no se han registrado recursos visuales que sean exclusivos de las manifestaciones registradas en materiales procedentes de contextos datados con posterioridad al año 1.250 d.C. En general, son los mismos GRV utilizados en los momentos previos al año 1.000 d.C. los que continúan utilizándose para la resolución de imágenes diversas en los rangos temporales posteriores. Sin embargo, se han definido GRV que son exclusivos de los contextos adscritos a momentos tempranos y que se discontinúan en momentos posteriores al año 1.000 d.C. También se identificaron ciertos GRV que presentan una situación inversa, ya que son minoritarios en los contextos adscritos a momentos tempranos y tienden a incrementar notablemente su frecuencia a partir de los momentos posteriores al año 1.250 d.C. Entonces, si bien hay formas específicamente tardías o tempranas de resolver una misma imagen 
también existen formas compartidas de hacerlo que trascienden estas "fronteras" temporales.

\section{Discusión}

Iniciamos este recorrido sosteniendo que es la gente que habita, transita y experimenta un paisaje específico la que lo construye apropiándose de él de formas diversas. Consideramos que a través del plasmado de ciertas imágenes se configuran lugares particulares definiéndose formas de mirar, interpretar e incorporar esos paisajes (Gell 1998; Ingold 2000; Morphy 2009). Pero destacamos que esas formas de mirar no son estáticas, sino dinámicas y van cambiando con el tiempo. Por lo tanto, nos orientamos a analizar la diversidad y la variabilidad de los soportes, los repertorios temáticos y los recursos visuales utilizados en las manifestaciones desplegadas en los materiales cerámicos de la región de Fiambalá, para definir sus particularidades, sus continuidades y discontinuidades en el tiempo.

Es importante volver a recordar que el problema aquí abordado no es autónomo, sino que está inserto dentro de los lineamientos y resultados del PACh-A. Esto es fundamental porque contextualiza e integra las manifestaciones plásticas dentro de la dinámica de un proceso regional que, entre los siglos IV y $\mathrm{XV}$, estuvo signado por períodos de despoblamiento y repoblamiento (ver supra). Creemos que en este proceso dinámico peculiar las manifestaciones visuales tienen un papel sustancial expresando las combinaciones que se dan a lo largo del tiempo entre los códigos de diseño, las preferencias estéticas y los modos de ver de sus realizadores.

En función de los análisis realizados fue posible comenzar a delinear la diversidad de soluciones plásticas aplicadas a los repertorios temáticos registrados en los soportes cerámicos considerados. Los resultados obtenidos para los materiales procedentes de contextos previos al año 1.000 d.C. apuntan a continuar sosteniendo que a lo largo de este amplio lapso existía un modo común de representación que indica que detrás de la diversidad de soluciones plásticas registradas existía una trayectoria de largo desarrollo local (Ratto et al. 2012). Por su parte, los resultados obtenidos para los materiales de contextos posteriores al año 1.250 d.C., permitieron observar que mientras algunas imágenes tendían a diluirse dentro del repertorio temático (por ejemplo las figuras felínicas) otras incrementaban su frecuencia (rectangulares, escalonados, quirquinchos y animales felinizados). Además comenzaron a registrarse manifestaciones que no tenían antecedentes en la muestra de momentos previos (ganchos, espirales, animales fantásticos, lechuzas, rostros humanos). A los Grupos de Soportes cerámicos que se registraban antes del año 1.000 d.C. se sumaron otros nuevos. Algo similar sucedió con los recursos visuales utilizados para la resolución de las imágenes, ya que si bien no se registraron soluciones plásticas propias de estos momentos tardíos, sino que son las de momentos más tempranos las que se utilizaron en la realización de las nuevas imágenes, la diversidad de Grupos de Recursos Visuales utilizados en cada una de las piezas tendió a incrementarse (Basile 2011).

Creemos que las observaciones realizadas sobre los materiales cerámicos de la muestra de momentos tardíos (posteriores al año 1.250 d.C.) pueden interpretarse en términos del ingreso de gente procedente del Norte de La Rioja y de los valles del oriente (Belén) (Figura 1). Este repoblamiento habría ocurrido en algún momento posterior a esa fecha cuando las condiciones ambientales de las tierras bajas del bolsón de Fiambalá comenzaron a recomponerse correspondiéndose posiblemente con la presencia incaica en la región, planteo que es coincidente con los resultados e hipótesis de trabajo de otras líneas analíticas dentro del proyecto general (Orgaz y Ratto 2012, 2013; Ratto 2013; Ratto y Boixadós 2012). En ese nuevo escenario comienzan a registrarse en la región nuevas formas de piezas y nuevas imágenes, de modo tal que reproducen las "formas de hacer" de los lugares de procedencia de sus realizadores. Entonces es posible pensar que esta gente continúa haciendo las "cosas" a su manera, en términos de "recetas" tecnológicas (Feely 2010), soportes e imágenes, pero no en forma aislada, sino en interacción dinámica con las poblaciones locales, incorporando imágenes y recursos visuales en formas de piezas propias, reinterpretándolas y adaptándolas a sus modos de ver. Podemos sostener entonces que estas imágenes desplegadas en la cerámica tardía (procedente de contextos datados con posterioridad al año 1.250 d.C.) presentan características distintivas respecto de las del primer milenio, pero incorporan elementos característicos de estas últimas dentro de sus propias estructuras. Sin embargo, la continuidad de ciertas formas de uso de los espacios plásticos, de los mismos recursos visuales y la perduración de algunas imágenes en el tiempo les otorga una unidad a lo largo del tiempo que es ineludible y 
que da cuenta de la articulación y del diálogo entre la gente que habitó la región de Fiambalá entre los siglos IV y XIV.

La decisión de colocar en un segundo plano las categorías estilísticas para enfocar los cambios y las continuidades en función de los rangos temporales de procedencia de los materiales analizados permitió establecer que en la región de Fiambalá existen manifestaciones, formas de uso de los espacios plásticos y recursos visuales que trascienden las fronteras de la clasificación estilística ${ }^{8}$. De haber encarado el análisis temporal a partir de estas categorías construidas para funcionar como reflejo de grupos de gente distintos de los contemporáneos o de los precedentes (Quiroga 2007) que derivan en compartimientos estancos que tienden a enfatizar las diferencias e ignorar los "inclasificables" (Scattolin 2007) se hubiera desalentado la búsqueda de las continuidades que nos permitieran ver la dinámica y el perfil particular que adquieren las manifestaciones visuales específicamente en la región de Fiambalá. Consideramos que la perspectiva propuesta permite comprender el proceso de habitar (sensu Ingold 2000) la región de manera más integral, vislumbrando la existencia de narrativas que continúan circulando y redefiniéndose a través de una memoria en permanente construcción, evitando la extrapolación temporal directa de las secuencias cerámicas extrarregionales que han conducido a desarticular un proceso que simplemente parece estar articulado de manera diferente.

Agradecimientos: Este trabajo es parte de mi investigación doctoral, desarrollada en el marco de una beca otorgada por el CONICET y de los proyectos Ubacyt F139 y Pict 2007-01539, ambos dirigidos por Norma Ratto. Sin su apoyo incondicional, su respeto y compromiso inagotables todo eso hubiera sido imposible. Agradezco también y como siempre, la generosidad enorme de Carlos Aschero y la confianza de Inés Gordillo; la ayuda de Dolores Carniglia con las traducciones y de Luis Coll con los mapas; la hospitalidad y calidez de quienes en Palo Blanco, Fiambalá y Las Papas nos reciben cada vez con las mismas ganas; la enorme colaboración brindada en todos los museos que visitamos; a Dánae Fiore por el impulso y respaldo constantes y a Gloria Cabello por el tiempo dedicado a la lectura de este manuscrito. Por último, agradezco particularmente a los evaluadores anónimos que con sus comentarios han contribuido a mejorar sustancialmente este trabajo.

\section{Referencias Citadas}

Aschero, C. 1975. Motivos y objetos decorados del sitio precerámico Inca Cueva 7 (provincia de Jujuy). Antiquitas 20-21:2-7.

_ _ _ _ 2006. Tramas en la piedra: rectángulos con diseños geométricos en Antofagasta de la sierra (puna meridional, Argentina). En Tramas en la Piedra. Producción y Usos del Arte Rupestre, editado por D. Fiore y M. M. Podestá, pp. 141-156. Asociación Amigos del Instituto Nacional de Antropología (AINA), World Archaeological Congress (WAC) y Sociedad Argentina de Antropología. Altuna Impresores, Buenos Aires.

_ _ _ 2013. Arte rupestre, Contexto y Sociedad en el Desierto Puneño. Tesis para optar al grado de Doctor en Arqueología. Facultad de Filosofía y Letras, Universidad de Buenos Aires, Buenos Aires.

Balesta, B. 2000. La Significación en la Funebria de La Ciénaga. Tesis optar al título de Doctor en Arqueología, Facultad de Ciencias Naturales y Museo, Universidad Nacional de La Plata, Buenos Aires.

Balesta, B. y V. Williams 2007. El análisis cerámico desde 1936 hasta nuestros días. Relaciones de la Sociedad Argentina de Antropología Tomo XXXII:169-190.

Balfet, H.; M. F. Fauvet-Berthelot y S. Monzon 1992. Normas para la Descripción de Vasijas Cerámicas. Centre D’Études Méxicaines et Centramméricaines, México.
Basile, M. 2011. Continuidades y Rupturas en las Representaciones Plásticas del Formativo (ca. 200 AD) a la Ocupación Incaica (ca. 1480 AD) en la Región de Fiambalá (Pcia. de Catamarca). Tesis optar al título de Doctor en Arqueología, Facultad de Filosofía y Letras, Universidad de Buenos Aires.

- - _ 2012 [2005]. Imágenes en Negro sobre Rojo. Apuntes para Delinear el Estilo cerámico Belén (ca. 1100-1535 A.D, Catamarca, Argentina). Editorial Académica Española. LAP Lambert Academic Publishing GmbH \& Co, Alemania.

2012. Imágenes, recursos visuales y soportes: un recorrido por las manifestaciones rupestres de la región de Fiambalá (Catamarca). Relaciones de la Sociedad Argentina de Antropología, Tomo XXXVII (2):413-434.

Basile, M. y N. Ratto 2011. Colores y surcos. Una propuesta metodológica para el análisis de las representaciones plásticas de la región de Fiambalá (Tinogasta, Catamarca, Argentina). Boletín del Museo Chileno de Arte Precolombino 16:75-88.

Black, M. 1983. ¿Cómo representan las imágenes? En Arte, Percepción y Realidad, editado por E.H. Gombrich, J. Hochberg, M. Black, pp. 127-169. Paidos, Buenos Aires.

Bonomo, N., A. Osella y N. Ratto 2010. Detecting and mapping buried buildings with GPR at an ancient village in Northwestern Argentina. Journal of Archaeological Science 37:3247-3255. 
Conkey, M. 1990. Experimenting with style in Archaeology, some historical and theoretical issues. En The Uses of Style in Archaeology, editado por M. Conkey y C. Hastdorf, pp. 5-17. Cambridge University Press, Cambridge.

Dreidemie, O. 1951. Un notable enterratorio. Mundo Atómico II(4):40-43.

- _ - 1953. Arqueología del valle de Abaucán. Mundo Atómico II(12):42-52.

Elkins, J. 2009. Un seminario sobre teoría de la imagen. Estudios Visuales 7:131-173.

Feely, A. 2010. Estilos tecnológicos y tradiciones cerámicas del bolsón de Fiambalá (Dto. Tinogasta, Catamarca). Tesis para optar el grado de Doctor en Arqueología, Facultad de Filosofía y Letras, Universidad de Buenos Aires.

Feely, A. y N. Ratto 2009. Variaciones de los conjuntos cerámicos de unidades domésticas: aldeas y puestos formativos del bolsón de Fiambalá (ca. 1500-1300 AP). En Entrelazando Ciencias: Sociedad y Ambiente Antes de la Conquista Española, compilado por N. Ratto, pp. 99-129. Eudeba, Buenos Aires.

Fiore, D., 2007. The economic side of rock art. Concepts on the production of visual images. Rock Art Research 24:149-160.

_ _ _ 2009. La materialidad del arte. Modelos económicos, tecnológicos y cognitivovisuales. En Perspectivas Actuales en Arqueología Argentina, compilado por R. Barberena, K. Borrazzo y L.A. Borrero, pp. 121-154. Editorial Dunken, Buenos Aires.

_. _ _ 2012. Materialidad visual y arqueología de la imagen. Perspectivas conceptuales y propuestas metodológicas desde el sur de Sudamérica. Boletín del Museo Chileno de Arte Precolombino 16:101-119.

Gallardo, F. 2005. Arte rupestre, contenido cultural de la forma e ideología durante el Formativo temprano en el Río Salado (Desierto de Atacama, Chile). TAPA 33:37-52.

Gardin, J.C. 1978. Code pour l'Analyse des Ornements. Editions du Centre National de la Recherche Scientifique, París.

Gell, A. 1998. Art and Agency. An Anthropological Theory. Clarendon Press, Oxford.

Gordillo, I. 2009. Dominios y recursos de la imagen. Iconografía cerámica del valle de Ambato. Estudios Atacameños. Arqueología y Antropología Surandinas 37:99-121.

González, A.R. y C. Sempé 1975. Prospección arqueológica en el valle de Abaucán. Revista del Instituto de Antropología Serie II:7-32.

Groupe $\mu$ 1993. Tratado del Signo Visual. Para una Retórica de la Imagen. Ediciones Cátedra S.A., Madrid.

Hammer, O., D. Harper y P. Ryan 2001. PAST: Palaeontological statistics software package for education y data analysis. Palaeontologia Electronica 4:9.

Ingold, T. 2000. The Perception of the Environment: Essays on Livelihood, Dwelling and Skill. Routledge, Londres.

Kandinsky 2007 [1926]. Punto y Línea sobre el Plano. Contribución al Análisis de los Elementos Pictóricos. Terramar Ediciones, La Plata.

Morphy, H. 2009. Art as a Mode of Action: Some Problems with Gell's Art and Agency. Journal of Material Culture 14:5-27.
Morphy, H. y M. Perkins 2006. The Anthropology of Art: A Reflection on its History and Contemporary Practice. Blackwell Publishing Ltd., Oxford.

Montero López, M.C., Hongn, F., Brod, J.A., Seggiaro, R., Marrett, R. y Sudo, M. 2010. Magmatismo Ácido del Mioceno Superior-Cuaternario en el área de Cerro Blanco-La Hoyada, Puna Sur. Revista de la Asociación Geológica Argentina 67 (2):327-346.

Orgaz, M. y N. Ratto 2012. Memoria y apropiación en paisajes agrícolas. En Arqueología y Espacialidad: Tendencias TeóricoMetodológicas y su Aplicación a la Cultura Material, editado por I. Gordillo y J.M. Vaquer, pp. 191:226. Abda - Yala, Quito.

_ _ _ 2013. Fragmentos del pasado en la ocupación incaica del oeste tinogasteño (Catamarca). En Delineando Prácticas de la Gente del Pasado: Los Procesos Socio-Históricos del Oeste Catamarqueño, compilado por N. Ratto, pp. 311-333. Serie Publicaciones. Sociedad Argentina de Antropología, Buenos Aires.

Orgaz, M., A. Feely y N. Ratto 2007. La cerámica como expresión de los aspectos socio-políticos, económicos y rituales de la ocupación Inka en la puna de Chaschuil y el valle de Fiambalá (Departamento Tinogasta, Catamarca, Argentina). En Procesos Sociales Prehispánicos en el Sur Andino. La Vivienda, la Comunidad y el Territorio, editado por A. Nielsen, C. Rivolta, V. Seldes, M. Vázquez y P. Mercolli, pp. 237-258. Editorial Brujas, Córdoba.

Páez, M.C. y M. Giovannetti 2008. Tipologizando Identidades: reflexiones sobre la construcción de identidades étnicas en la Arqueología del NOA. Avá No 13, Posadas [online] 13:1-21. Disponible en http://www.scielo.org.ar/scielo.php?script=sci_arttext\&.Citado 01-06-2011.

Quiroga, L. 2007. Del texto a la representación cartográfica: Interpretaciones sobre la variabilidad estilística en la arqueología del Noroeste Argentino. Ponencia presentada en la IV Reunión internacional de teoría arqueológica en Suramérica (TAAS), 3 al 7 de Julio, San Fernando del Valle de Catamarca, Catamarca.

Ratto, N. 2007. Paisajes Arqueológicos en el Tiempo: La interrelación de ciencias sociales, físico-químicas y paleoambientales (Dpto. Tinogasta, Catamarca, Argentina). En Producción y Circulación Prehispánicas de Bienes en el Sur Andino, compilado por A. Nielsen, M.C. Rivolta, V. Seldes, M. Vázquez y P. Mercolli, pp. 35-54. Editorial Brujas, Córdoba.

_ _ _ 2013. A modo de introducción: la articulación de estudios arqueológicos, paleoambientales e históricos en el oeste tinogasteño (Catamarca). En Delineando Prácticas de la Gente del Pasado: Los Procesos Socio-Históricos del Oeste Catamarqueño, compilado por N. Ratto, pp. 17-44. Serie Publicaciones. Sociedad Argentina de Antropología, Buenos Aires.

Ratto, N. y M. Basile 2010. La localidad arqueológica de Palo Blanco (Dpto. Tinogasta, Catamarca): Nuevas Evidencias. En Arqueología Argentina en el Bicentenario de la Revolución de Mayo, editado por J.R. Bárcena y H. Chiavazza, Tomo IV, pp. 1707-1712. Universidad Nacional de Cuyo, Mendoza.

_ _ _ 2013. Funebria y animales (ca.1250-1550 ad): una primera aproximación para el oeste tinogasteño, Catamarca, Argentina. En Delineando Prácticas de la Gente del Pasado: Los Procesos Socio-Históricos del Oeste Catamarqueño, compilado por N. Ratto, pp. 251-280. Serie Publicaciones. Sociedad Argentina de Antropología, Buenos Aires. 
Ratto, N., M. Basile y A. Feely 2012. Rutas y espacios conectados: las tierras altas y bajas del oeste tinogasteño de Catamarca (CA. 2.000-1.000 A.P.). Revista de Antropología Chilena 26:33-58.

Ratto, N. y R. Boixadós 2012. Arqueología y Etnohistoria. La construcción de un problema de investigación (Abaucán, Tinogasta, Catamarca). Memoria Americana 20 (2):187-220.

Ratto, N. y M. De Nigris 2012. El consumo de camélidos (Vicugna vicugna) en un sitio ceremonial de la alta cordillera andina (Departamento Tinogasta, Catamarca, Argentina). Chungara Revista de Antropología Chilena 44:287-298.

Ratto, N., A. Feely y M. Basile 2007. Coexistencia de diseños tecno-estilísticos en el Período Tardío preincaico: el caso del entierro en urna del bebé de La Troya (Tinogasta, Catamarca, Argentina). Intersecciones en Antropología 8:15-31.

Ratto, N., A. Feely y P. Salminci 2008. Diseños arquitectónicos y propiedades del registro arqueológico cerámico en el valle de Fiambalá (Departamento Tinogasta, Catamarca) En Problemáticas de la Arqueología Contemporánea II, compilado por A. Austral y M. Tamagnini, pp. 771-775. Universidad Nacional de Río Cuarto.Ratto, Córdoba.

Ratto, N., M.C. Montero, F. Hongn y B. Valero Garcés 2013. La historia ambiental de las sociedades productivas del oeste tinogasteño (Catamarca), siglos I a XVI. En Delineando Prácticas de la Gente del Pasado: Los Procesos Socio-Históricos del Oeste Catamarqueño, compilado por N. Ratto, pp. 45-66.
Serie Publicaciones. Sociedad Argentina de Antropología, Buenos Aires.

Ratto, N., M. Orgaz y R. Plá 2004. La Explotación del Alfar de La Troya en el Tiempo: Casualidad o Memoria (Departamento Tinogasta, Catamarca, Argentina. Chungara Revista de Antropología Chilena 36:349-361.

Sempé, C. 1976. Contribución a la Arqueología del Valle de Abaucán. Tesis para optar el grado de Doctor en Arqueología, Facultad de Ciencias Naturales y Museo, Universidad Nacional de La Plata, La Plata.

_ _ _ 1977. Las culturas agroalfareras prehispánicas del valle de Abaucán (Tinogasta-Catamarca). Relaciones de la Sociedad Argentina de Antropología (NS) T XI:55-68.

Scattolin, C. 2007. Estilos como recursos en el Noroeste Argentino. En Procesos Sociales Prehispánicos en los Andes Meridionales, la Vivienda, la Comunidad y el Territorio, compilado por A. Nielsen, M. C. Rivolta, V. Seldes, M. Vázquez y P. Mercolli, pp. 291-322. Editorial Brujas, Córdoba.

Scott, R. 1962 [1951]. Fundamentos del Diseño. Lerú, Buenos Aires.

Stuiver, M. y P.J. Reimer 1993. Radiocarbon Calibration Program. Calib Rev 6.0. Radiocarbon 35:215-230.

Wynveldt, F. 2007. La estructura de diseño decorativo en la cerámica Belén (noroeste argentino). Boletín del Museo Chileno de Arte Precolombino 12:49-67.

\section{Notas}

1 Este es el nombre genérico dado a distintos proyectos que a lo largo de la historia han sido financiados por organismos científico-académicos (Universidad Nacional de Catamarca, Universidad de Buenos Aires, Agencia Nacional de Promoción Científica y Tecnológica, entre otros) bajo la dirección de la Dra. N. Ratto.

2 En el caso de las piezas abiertas se duplicó el área lateral externa calculada, ya que toda la superficie interna resulta accesible. En cambio, para las piezas cerradas sólo se consideró el área interna del borde y cuello dado que el resto de la superficie interior presenta un acceso limitado para la intervención visual.

3 Aclaramos que cada una de las imágenes constituye una unidad visual y conceptual que puede estar definida por la percepción de una contigüidad lineal o de una tensión espacial resultante de la proximidad. Al respecto, el concepto de contigüidad lineal remite a la definición de imágenes que se recortan del fondo por el delineado de un contorno continuo que las unifica, mientras que el de tensión espacial define el efecto de la atracción resultante de la proximidad existente entre elementos de la imagen que si bien no están unidos por contigüidad lineal, son percibidos por los observadores como una unidad que se segrega del fondo (Scott 1962 [1951]). De esta manera, todas las imágenes de la muestra que incluyen trazos aislados, agrupados y rostros antropomorfos son analizadas al mismo nivel de resolución.

4 Método Ward y distancia Euclidiana

5 La combinación de tratamientos numéricos multivariados se realizó con los programas estadísticos PAST (Hammer et al. 2001) y SPSS 15.0.

6 Se aclara que sólo para el caso de los materiales de colecciones que no han podido ser datados se utilizó para su ubicación temporal el lapso definido por las dataciones mínimas y máximas disponibles para las áreas de procedencia de esas muestras (Basile 2011).

7 El criterio utilizado para diferenciar los diseños no figurativos primarios de los compuestos fue que: (i) los primeros se resuelven mediante una única UM, mientras que (ii) los compuestos se definen mediante la combinación de dos o más.

8 Se observó que piezas correspondientes a estilos como Saujil, Ciénaga y Aguada, adscritos al período Formativo en sentido amplio, y Belén, Sanagasta y Belén III, adscritas al período de Desarrollo Regionales o período Intermedio Tardío se integran en los mismos Grupos de Soportes y comparten cierto tipo de imágenes y formas de resolverlas visualmente (iguales Grupos de Recursos Visuales). 
